\title{
Evaluation of Knowledge Management Tools by Using An Interval Type-2 Fuzzy TOPSIS Method
}

\author{
Gülçin Büyüközkan $^{1}{ }^{*}$, Ismail Burak Parlak ${ }^{2}$, A. Cagri Tolga ${ }^{1}$ \\ ${ }^{1}$ Department of Industrial Engineering, Galatasaray University, \\ Ciragan Cad. 34349 \\ Ortakoy, Istanbul, Turkey \\ E-mail: gulcin.buyukozkan@gmail.com,ctolga@gsu.edu.tr \\ 2 Department of Computer Engineering, Galatasaray University, \\ Ciragan Cad. 34349 \\ Ortakoy, Istanbul, Turkey \\ E-mail: bparlak@gsu.edu.tr
}

Received 17 June 2015

Accepted 14 April 2016

\begin{abstract}
Knowledge management (KM) systems can provide businesses a wide range of advantages and efficiency improvements. Increasing competition forces companies to seek new ways to streamline their processes and manage their information and knowledge better, leading to increased demand for KM solutions. Considering various needs of organizations and diverse features of available KM alternatives, choosing the most suitable KM tool is an important decision for businesses. The contribution of this paper to the KM literature is a KM evaluation framework for decision makers to compare available KM products of different vendors by first identifying relevant evaluation criteria and then proposing a group decision making framework using the Interval Type-2 TOPSIS technique. This method has more flexibility in handling uncertainties compared to the Type-1 fuzzy sets and enables decision makers to effectively analyze, compare and select the most appropriate KM tools. The framework is also used in a case study for the sake of demonstrating its potential in businesses.
\end{abstract}

Keywords: Interval Type-2 fuzzy sets, Fuzzy multiple attributes group decision making, TOPSIS, KM tools selection

\section{Introduction}

Successful knowledge management (KM) can support businesses in obtaining sustainable competitive advantage for businesses $1,2,3,4,5$. This raises interest of industry managers and academicians. KM tools are information technology (IT) based systems which support and improve those processes that aim to create, store, retrieve, transfer and apply knowledge ${ }^{6}$. These tools do not only enable businesses to transfer knowledge to its departments, but also integrate many knowledge processes for solving business problems as an organizational information system ${ }^{7,8}$. Furthermore, KM tools promote and facilitate knowledge processes in decision-making and can be used as enablers in supply chain management

\footnotetext{
*Corresponding author: E-mail:gulcin.buyukozkan@gmail.com Tel:+90 212227 4480-, Fax: +90 2122595557.
} 
for connecting an enterprise with its customers and suppliers $9,10,11$.

There exist various KM software that have specific functionalities that suit different needs of organizations, requiring companies to reach a decision in selecting the most appropriate software solution among many in the market. Taking the significant amounts of financial investment as well as the potential risks and benefits into account, selection of a suitable KM tool represents an important corporate decision ${ }^{12}$. On the other hand, there are many KM system alternatives and each alternative can affect different stakeholders within a company. Considering the overall complexity of business activities and resource limitations, finding the most suitable KM tool is a difficult and time intensive task. Because of these challenges, the selection of a suitable KM is a decision making problem that is not fully defined yet.

When selecting the most suitable KM software, there are many criteria to consider and different decision makers (DMs) to consult. This adds up to the complexity of the solution process and necessitates a sound, systematic approach for critically assessing available KM tool alternatives and identifying the most suitable one. The aim is not only to choose the best alternative among many, but also to decrease the time and effort used for taking the decision and for building consensus among DMs. Addressing this research gap ${ }^{12,13,14,15,16}$, this article proposes an assessment framework that can provide a way to effectively evaluate the available KM tool alternatives.

There are many different factors that can come into question when selecting one tool from many different alternatives. Therefore, a multi criteria analysis and solution approach can be followed for this $\mathrm{KM}$ tool evaluation problem. There are many useful multi criteria decision making (MCDM) methods available to decision makers, with their advantages and drawbacks. This paper uses a decision framework which makes use of the Interval Type-2 fuzzy TOPSIS method. As expert opinions constitute a significant and integral component of this process, fuzzy data will need to be evaluated. To deal with uncertainty in alternative selection and to overcome the vagueness limitations of MCDM methods, var- ious authors utilized fuzzy sets ${ }^{17}$. Ordinary fuzzy sets (type-1) ${ }^{18}$ can cover uncertainties of linguistic words to some extent. However, Interval Type-2 fuzzy sets ${ }^{19}$ are preferable for gaining more degrees of freedom for handling the unavoidable fuzziness and uncertainty of real world conditions ${ }^{20,21}$.

During this study, the focus is about the analysis of KM tools using a fuzzy framework. The study differs from the literature of KM tools as it uses a MCDM technique with Interval Type-2 fuzzy sets. Therefore, the analysis can better handle the uncertainty and encompass the fuzzy decision in the case of KM. Even if similar management tools are studied with Type-1 fuzzy sets, there is no study about the selection of KM tools by applying Interval Type-2 fuzzy sets. In order to highlight the robustness of our framework, the selection problem is also resolved with the Type-1 fuzzy sets and crisp approach. The motivation of our analysis is guided by the literature review where the selection problem of KM tools represent high uncertainty and critical availability. Furthermore, our analysis denotes a quantitative contribution to the KM problem by indicating how this problem might be dealt with high uncertainty to select the appropriate software environment.

The article is structured in the following order; Section 2 introduces the proposed valuation framework and right after that in Section 3 algebraic operations of Interval Type-2 fuzzy sets and their ranking are given. Section 4 presents the computational steps of the proposed methodology using the method called Interval Type-2 fuzzy TOPSIS. Following that, Section 5 applies the framework on a KM tool selection case for a private company in Turkey. As the final part, Section 6 discusses the results and provides the concluding remarks.

\section{KM tools evaluation framework}

\subsection{Literature Survey of KM tools evaluation}

$\mathrm{KM}$ tools in the software market have different features, parallel to improvements in IT and multiple, changing needs in numerous industries and sometimes conflicting objectives. From a business perspective, the proliferation of a high number of soft- 
ware systems furthermore complicates the decision making procedure. Influencing factors complicating the tasks of DMs can be summarized as below:

- Users with insufficient experience.

- Continuous advancement and improvements in IT.

- Abundance of different commercial KM software products.

- Possible hardware-software compatibility problems.

- Functional disparities among software packages.

In related literature about KM tool selection, Ngai and Chan ${ }^{12}$ made use of a model based on Analytic Hierarchy Process (AHP) ${ }^{27}$ to support decision makers in evaluating different alternatives of $\mathrm{KM}$ products and applied the framework on a case study, underlining that their primary focus was the framework they proposed. Considering that the selection of an appropriate KM tool inevitably involves subjective evaluation, Liu and Peng ${ }^{13}$ used a fuzzy AHP model in their paper. Büyüközkan and Feyzioğlu ${ }^{28}$ applied a Choquet integral based aggregation methodology to rate KM systems of different vendors. In another article, $\mathrm{Yu}^{14}$ established an evaluation system that combined a qualitative index with a quantitative index based on the features of the KM system of the enterprise, and constructed an extended evaluation based matter-element model of the system. Büyüközkan et al. ${ }^{15}$ presented a fuzzy VIKOR method which used fuzzy logic as well as group decision making approaches to handle the vagueness and granularity of linguistic expressions. In order to support the evaluation and selection of $\mathrm{KM}$ systems from the users perspective, $\mathrm{Li}$ et al ${ }^{16}$, recently used an MCDM approach which combines quality function deployment (QFD) with TOPSIS in intuitionistic fuzzy environment.

Until recently, Type-1 fuzzy logic was used more frequently in research papers. However, related literature is witnessing a surge in the use of Type-2 fuzzy logic ${ }^{29}$. Type- 1 fuzzy set is based on the assumption of certainty in the membership function definitions. On the other hand, the membership functions of Type-2 fuzzy sets have 3 dimensions and do take uncertainty into account. This added third dimension and the footprint of uncertainty are two novelties of Type-2 fuzzy sets which represent new degrees of freedom, enabling direct modeling and handling uncertainties. Considering that human decisions and expressions involve uncertainty, type2 fuzzy sets present a more suitable approach for handling the subjectivity and the membership imprecision of model. Therefore, this paper uses a decision framework that is based on the technique of Interval Type-2 fuzzy TOPSIS. This is original because there is no other research combining the Interval Type-2 fuzzy and TOPSIS methods for evaluating software alternatives or KM tool selection problems.

\subsection{KM tools evaluation criteria}

The evaluation criteria are determined based on various information sources, including product briefings, software demos, vendor surveys and a careful literature study $12,16,28,30,31,33,34,35$. In order to ensure that the identified criteria are sufficiently well formulated and properly understood, the topic is discussed with DMs and the criteria are validated by external professional experts (KM consultants and vendors themselves). The following criteria are determined for the KM tool evaluation:

- Software enhancement possibilities (C1): KM tools are an integral part of other applications used in IT systems of a company. Therefore, interface with exchange servers, project reports, Enterprise Resource Planning and finance systems or their relevant parameters need to be flexible enough. A KM tool should be able to allow new functions that are developed from scratch and provide a platform where additional development can easily be made.

- Compliance with company standards (C2): In a global company working in several geographic locations, a wide range of products are needed. Isolated, local solutions can lead to complexities and even disorders in terms of application integration and reporting, leading to time consumption, inefficiency and additional cost. Standardization of IT applications can provide benefits in this respect, where the software complies with the standards of the company. 
- Document management (C3): Knowledge organizations embed big volumes of data into documents, which can increase productivity if documents are managed effectively. Proper document management systems need to include features like exhaustive authorization options, alerts, handy searching mechanisms, discussions and versioning for documents, beside others.

- Collaboration (C4): Collaboration is one of the fundamental evaluation criteria of KM tools, as it can leverage implicit knowledge. Teamwork, communication within teams, and collaborative solutions produce a considerable proportion of knowledge assets. Furthermore, collaboration is an important component for an e-business (the other two components being information and commerce).

- Portal functions (C5): Portals are user-friendly entry points into the corporate knowledge domain of a company. Portals are expected to be user friendly and customizable for users, and are expected to have the capability for using several carefully selected applications with a single signin.

- Workflow facilities (C6): In a business, workflow management connects management of documents with the management of processes, where workflow facilities are expected to hasten the flow of documents through the internal processes. The path a document travels within a company is defined and responsibilities and actions on the document are described, such as rejection and approval functions and the person in charge of that function.

- User Friendliness (C7): Integration of KM products can have change management dimensions in an organization. A KM system that is not user friendly can delay its adoption, lead to internal resistance and ultimately to inefficiency. Such difficulties may even prevent project teams from successfully implement the KM system, causing additional challenges. Clearly, a user friendly KM system will be more easily accepted within an organizations across departments.

- Purchasing costs (C8): Similar to many other decision making problems, purchase decisions are largely affected by the up-front costs such as KM software purchasing, setting up and training.

- Operating costs (C9): Operating costs are defined as running costs needed for continuing everyday operations of a KM tool.

- Vendor performance (C10): Vendors are business partners who are expected to ensure a certain level of service quality and support provided to customers. Vendors with sufficient expertise and experience with the KM will give customers more confidence. The stability of the vendor is another important dimension, where its financial status, scale and local support level should not be neglected.

\section{The Ranking Values and the Arithmetic Operations of Interval Type-2 Fuzzy Sets}

The definitions and operations on Type- 2 fuzzy sets has to be given in order to be more luminous about the trapezoidal Interval Type-2 fuzzy numbers. The definitions in the study of Chen and Lee ${ }^{24}$ are taken in this study for their clarity. Moreover, the ranking method derived from the article of $\mathrm{Wu}$ and Mendel ${ }^{36}$ is used in the proposed study because of its appropriateness and accuracy.

Let $\tilde{A}$ be a Type- 1 trapezoidal fuzzy set, $\tilde{A}=$ $\left(a_{1}, a_{2}, a_{3}, a_{4} ; H_{1}(\tilde{A}), H_{2}(\tilde{A})\right)$, where $H_{1}(\tilde{A})$ states the membership value of the element $a_{2} ; H_{2}(\tilde{A})$ states the membership value of the element $a_{3} ; 0 \leqslant$ $H_{1}(\tilde{A}) \leqslant 1$ and $0 \leqslant H_{2}(\tilde{A}) \leqslant 1$. As Mendel et al. ${ }^{20}$ defined; a Type-2 fuzzy set $\tilde{\tilde{A}}$ in the universe of discourse $X$ can be displayed by a Type- 2 membership function shown $\mu_{\tilde{A}}$, as follows:

$$
\tilde{\tilde{A}}=\left\{\left((x, u), \mu_{\tilde{\tilde{A}}}(x, u)\right) \mid \forall x \in X, \forall u \in A_{x} \subseteq[0,1]\right\}
$$

where $J_{x}$ denotes an interval in $[0,1]$. The Type-2 fuzzy set $\tilde{\tilde{A}}$ also can be interpreted as follows:

$$
\tilde{\tilde{A}}=\int_{x \in X} \int_{u \in J_{x}} \mu_{\tilde{\tilde{A}}}(x, u) /(x, u)
$$

where $A_{x} \subseteq[0,1]$ and $\iint$ states the union over all admissible $x$ and $u$. And additionally they called $\tilde{\tilde{A}}$ as an Interval Type-2 fuzzy set if all $\mu_{\tilde{A}}(x, u)=1$ 
20. An Interval Type-2 fuzzy set $\tilde{\tilde{A}}$ can be considered as a special case of a Type-2 fuzzy set, shown as follows:

$$
\tilde{\tilde{A}}=\int_{x \in X} \int_{u \in A_{x}} 1 /(x, u)
$$

where $A_{x} \subseteq[0,1]$. Chen and Lee ${ }^{24}$ adopted the definition of upper and lower membership functions of an Interval Type- 2 fuzzy sets to the trapezoidal Interval Type-2 fuzzy set as follows;

$$
\begin{aligned}
& \tilde{\tilde{A}}_{i}=\left(\tilde{A}_{i}^{U}, \tilde{A}_{i}^{L}\right)=\left(\left(a_{i 1}^{U}, a_{i 2}^{U}, a_{i 3}^{U}, a_{i 4}^{U} ; H_{1}\left(\tilde{A}_{i}^{U}\right), H_{2}\left(\tilde{A}_{i}^{U}\right)\right),\right. \\
& \left(a_{i 1}^{L}, a_{i 2}^{L}, a_{i 3}^{L}, a_{i 4}^{L} ; H_{1}\left(\tilde{A}_{i}^{L}\right), H_{2}\left(\tilde{A}_{i}^{L}\right)\right)
\end{aligned}
$$

where $H_{j}\left(\tilde{A}_{i}^{U}\right)$ states the membership value of the element $a_{i(j+1)}^{U}$ in the upper trapezoidal membership function $\tilde{A}_{i}^{U}, 1 \leqslant j \leqslant 2, H_{j}\left(\tilde{A}_{i}^{L}\right)$ denotes the membership value of the element $a_{i(j+1)}^{L}$ in the lower trapezoidal membership function $\tilde{A}_{i}^{L}, 1 \leqslant j \leqslant 2$, $H_{1}\left(\tilde{A}_{i}^{U}\right) \in[0,1], H_{2}\left(\tilde{A}_{i}^{U}\right) \in[0,1], H_{1}\left(\tilde{A}_{i}^{L}\right) \in[0,1]$, $H_{2}\left(\tilde{A}_{i}^{L}\right) \in[0,1]$, and $1 \leqslant i \leqslant n$.

Let $\tilde{\tilde{A}}$ be an Interval Type-2 fuzzy set $\tilde{\tilde{A}}=$ $\left(\tilde{A}^{U}, \tilde{A}^{L}\right)$ in the universe of discourse $X$. If $\tilde{A}^{U}=\tilde{A}^{L}$, then the Interval Type-2 fuzzy set $\tilde{\tilde{A}}$ turns into a Type-1 fuzzy set. Let $\tilde{A}$ be a Type- 1 fuzzy set, where $\tilde{A}=\left(a_{1}, a_{2}, a_{3}, a_{4} ; H_{1}(\tilde{A}), H_{2}(\tilde{A})\right)$. Then, the Type-1 fuzzy set $\tilde{A}$ also can be extended into the Interval Type-2 fuzzy set representation, i.e.,

$$
\begin{aligned}
& \tilde{\tilde{A}}=\left(\left(a_{1}, a_{2}, a_{3}, a_{4} ; H_{1}(\tilde{A}), H_{2}(\tilde{A})\right),\right. \\
& \left(a_{1}, a_{2}, a_{3}, a_{4} ; H_{1}(\tilde{A}), H_{2}(\tilde{A})\right) .
\end{aligned}
$$

\subsection{Arithmetic operations on trapezoidal Interval Type-2 fuzzy sets}

The arithmetic operations that are quoted from Lee and Chen ${ }^{37}$ between trapezoidal Interval Type-2 fuzzy sets will be reviewed in this subsection. Let us assume two trapezoidal Interval Type-2 fuzzy sets as follows:

$$
\begin{aligned}
& \tilde{\tilde{A}}_{1}=\left(\tilde{A}_{1}^{U}, \tilde{A}_{1}^{L}\right)=\left(\left(a_{11}^{U}, a_{12}^{U}, a_{13}^{U}, a_{14}^{U} ; H_{1}\left(\tilde{A}_{1}^{U}\right), H_{2}\left(\tilde{A}_{1}^{U}\right)\right),\right. \\
& \left(a_{11}^{L}, a_{12}^{L}, a_{13}^{L}, a_{14}^{L} ; H_{1}\left(\tilde{A}_{1}^{L}\right), H_{2}\left(\tilde{A}_{1}^{L}\right)\right. \\
& \tilde{\tilde{A}}_{2}=\left(\tilde{A}_{2}^{U}, \tilde{A}_{2}^{L}\right)=\left(\left(a_{21}^{U}, a_{22}^{U}, a_{23}^{U}, a_{24}^{U} ; H_{1}\left(\tilde{A}_{2}^{U}\right), H_{2}\left(\tilde{A}_{2}^{U}\right)\right),\right. \\
& \left(a_{21}^{L}, a_{22}^{L}, a_{23}^{L}, a_{24}^{L} ; H_{1}\left(\tilde{A}_{2}^{L}\right), H_{2}\left(\tilde{A}_{2}^{L}\right)\right.
\end{aligned}
$$

The addition, subtraction, and multiplication operations between two trapezoidal Interval Type-2 fuzzy sets $\tilde{\tilde{A}}_{1}$ and $\tilde{\tilde{A}}_{2}$ and operation between the trapezoidal Interval Type- 2 fuzzy set $\tilde{\tilde{A}}_{1}$ and the crisp value $k$ are depicted in the following equations:

$$
\begin{aligned}
& \tilde{\tilde{A}}_{1} \oplus \tilde{\tilde{A}}_{2}=\left(\tilde{A}_{1}^{U}, \tilde{A}_{1}^{L}\right) \oplus\left(\tilde{A}_{2}^{U}, \tilde{A}_{2}^{L}\right)= \\
& \left(\left(a_{11}^{U}+a_{21}^{U}, a_{12}^{U}+a_{22}^{U}, a_{13}^{U}+a_{23}^{U}, a_{14}^{U}+a_{24}^{U} ;\right.\right. \\
& \min \left(H_{1}\left(\tilde{A}_{1}^{U}\right), H_{1}\left(\tilde{A}_{2}^{U}\right)\right), \min \left(H_{2}\left(\tilde{A}_{1}^{U}\right), H_{2}\left(\tilde{A}_{2}^{U}\right)\right), \\
& \left(\left(a_{11}^{L}+a_{21}^{L}, a_{12}^{L}+a_{22}^{L}, a_{13}^{L}+a_{23}^{L}, a_{14}^{L}+a_{24}^{L} ;\right.\right. \\
& \min \left(H_{1}\left(\tilde{A}_{1}^{L}\right), H_{1}\left(\tilde{A}_{2}^{L}\right)\right), \min \left(H_{2}\left(\tilde{A}_{1}^{L}\right), H_{2}\left(\tilde{A}_{2}^{L}\right)\right) \\
& \tilde{\tilde{A}}_{1} \otimes \tilde{\tilde{A}}_{2}=\left(\tilde{A}_{1}^{U}, \tilde{A}_{1}^{L}\right) \otimes\left(\tilde{A}_{2}^{U}, \tilde{A}_{2}^{L}\right)= \\
& \left(\left(a_{11}^{U} \times a_{21}^{U}, a_{12}^{U} \times a_{22}^{U}, a_{13}^{U} \times a_{23}^{U}, a_{14}^{U} \times a_{24}^{U} ;\right.\right. \\
& \min \left(H_{1}\left(\tilde{A}_{1}^{U}\right), H_{1}\left(\tilde{A}_{2}^{U}\right)\right), \min \left(H_{2}\left(\tilde{A}_{1}^{U}\right), H_{2}\left(\tilde{A}_{2}^{U}\right)\right), \\
& \left(\left(a_{11}^{L} \times a_{21}^{L}, a_{12}^{L} \times a_{22}^{L}, a_{13}^{L} \times a_{23}^{L}, a_{14}^{L} \times a_{24}^{L} ;\right.\right. \\
& \min \left(H_{1}\left(\tilde{A}_{1}^{L}\right), H_{1}\left(\tilde{A}_{2}^{L}\right)\right), \min \left(H_{2}\left(\tilde{A}_{1}^{L}\right), H_{2}\left(\tilde{A}_{2}^{L}\right)\right) \\
& \tilde{\tilde{A}}_{1}=\left(k \times a_{11}^{U}, k \times a_{12}^{U}, k \times a_{13}^{U}, k \times a_{14}^{U} ; H_{1}\left(\tilde{A}_{1}^{U}\right), H_{2}\left(\tilde{A}_{1}^{U}\right)\right), \\
& \left.\left.\left(k \times a_{1}^{L}, k \times a_{1}^{L}, k \times a_{1}^{L}, k \times \tilde{A}_{L}, H_{1} L\right), H_{1}\right)\right),
\end{aligned}
$$

\subsection{Ranking of trapezoidal Interval Type-2 fuzzy sets}

A centroid based ranking method developed by $\mathrm{Wu}$ and Mendel ${ }^{36}$ will be used as a ranking operation in this study. Unlike the work of Chen and Lee ${ }^{24}$, this method is preferred because it is more efficient and easy to understand. The ranking method can be viewed as a generalization of Yager's first ranking method for Type-1 fuzzy sets ${ }^{38}$ to Interval Type- 2 fuzzy sets.

The centroid $C(\tilde{A})$ of an Interval Type-2 fuzzy set $\tilde{\tilde{A}}$ is the union of the centroids of all its embedded Type- 1 fuzzy sets, $A_{e}$, i.e.,

$$
\varphi(\tilde{A}) \equiv \bigcup_{\forall A_{e}} c\left(A_{e}\right)=\left[c_{l}(\tilde{A}), c_{r}(\tilde{A})\right],
$$

where $U$ is is the union operation, and

$$
\begin{gathered}
c_{l}(\tilde{A})=\min _{\forall A_{e}} c\left(A_{e}\right), \\
c_{r}(\tilde{A})=\max _{\forall A_{e}} c\left(A_{e}\right), \\
c\left(A_{e}\right)=\frac{\sum_{i=1}^{N} x_{i} \mu_{A_{e}}\left(x_{i}\right)}{\sum_{i=1}^{N} \mu_{A_{e}}\left(x_{i}\right)},
\end{gathered}
$$


In addition $c_{l}(\tilde{A})$ and $c_{r}(\tilde{A})$ can be expressed as:

$$
\begin{gathered}
c_{l}(\tilde{A})=\frac{\sum_{i=1}^{L} x_{i} \bar{\mu}_{\tilde{A}}\left(x_{i}\right)+\sum_{i=L+1}^{N} x_{i} \underline{\mu}_{\tilde{\tilde{A}}}\left(x_{i}\right)}{\sum_{i=1}^{L} \bar{\mu}_{\tilde{A}}\left(x_{i}\right)+\sum_{i=L+1}^{N} \underline{\mu}_{\tilde{A}}\left(x_{i}\right)}, \\
c_{r}(\tilde{A})=\frac{\sum_{i=1}^{R} x_{i} \underline{\mu}_{\tilde{A}}\left(x_{i}\right)+\sum_{i=R+1}^{N} x_{i} \bar{\mu}_{\tilde{A}}\left(x_{i}\right)}{\sum_{i=1}^{R} \underline{\mu}_{\tilde{A}}\left(x_{i}\right)+\sum_{i=R+1}^{N} \bar{\mu}_{\tilde{A}}\left(x_{i}\right)},
\end{gathered}
$$

Switch points $L$ and $R$, as well as $c_{l}(\tilde{A})$ and $c_{r}(\tilde{A})$, are computed by iterative KM algorithms.

Centroid-based ranking method: First compute the average centroid for each Interval Type-2 fuzzy set $\tilde{\tilde{A}}_{i}$,

$$
c\left(\tilde{\tilde{A}}_{i}\right)=\frac{c_{l}\left(\tilde{A}_{i}\right)+c_{r}\left(\tilde{A}_{i}\right)}{2}, i=1, \ldots, N
$$

and then sort $c\left(\tilde{\tilde{A}}_{i}\right)$ to obtain the rank of $\tilde{\tilde{A}}_{i}$.

\section{Interval Type-2 Fuzzy TOPSIS Method in a Group Decision Making Setting}

\subsection{Literature survey of Type-2 Methods}

A technique that is often applied in MCDM is "Technique for Order Preference by Similarity to Ideal Solution" (TOPSIS) ${ }^{22}$. It is an efficient methodology that is able to provide decision makers with an indisputable preference order ${ }^{23}$. The hybrid decision making framework proposed in this article has the benefit of making use of the advantages of both TOPSIS and Type- 2 fuzzy set methods ${ }^{24}$. Recently, Chatterjee and Kar ${ }^{25}$ combined these methods to evaluate the risky nature of six financial institutions of supply chain management. Moreover, Celik et al. ${ }^{26}$ made use of these methods to assess and improve passenger satisfaction in the systems of public transportation. Interval Type-2 fuzzy TOPSIS method is first familiarized by Chen and Lee ${ }^{24}$. Our study utilizes a modified version of this Interval Type-2 TOPSIS method.

Although it is a hot topic, there are relatively few studies. The service quality of public transportation systems in Istanbul are discussed with the opinions of the passengers by Celik et al. ${ }^{26}$. They assessed the satisfaction levels of passengers of Istanbul's public transportation system first with a questionnaire and then with statistical methods. For these purposes, the Interval Type-2 fuzzy technique has been used in conjuction with TOPSIS and GRA methods. In another paper, Cebi and Otay ${ }^{39}$ introduced the application of fuzzy TOPSIS method with Interval Type- 2 fuzzy sets on a facility location selection problem for a cement factory. Chen et al. ${ }^{41}$ extended the QUALIFLEX method for dealing with MCDM problems in an Interval Type-2 environment. The quoted study explicated the convenience and practicability of the presented techniques for a medical (acute inflammatory demyelinating disease) MCDM problem. The validity of the proposed model is then verified with the help of a comparative analysis using another outranking technique. Celik et al. ${ }^{42}$ discussed the improvement of satisfaction levels in the municipal rail transit network of Istanbul city. In their article, the authors evaluated customer satisfaction level with VIKOR method. Another interesting study ${ }^{43}$ integrated the techniques of GRA, interval-valued fuzzy sets and VIKOR for the sake of evaluating the service quality of a Chinese cross-strait airlines company, with the help of passenger questionnaires.

A Type-2 fuzzy sets extended fuzzy analytic hierarchy process was developed by Kahraman et al. 44. They applied their advanced model to a supplier selection problem. Ghorabaee et al. ${ }^{45}$ offered another multi criteria model with Interval Type-2 sets integrated fuzzy COPRAS method in the selection process of suppliers. An extension of MULTIMOORA method, another MCDM technique by Interval Type-2 fuzzy sets was provided by Baležentis and Zeng ${ }^{46}$ for a personnel selection problem. Chen 47 developed an extension of ELECTRE method with Type-2 fuzzy sets and presented the signed distance-based hybrid averaging operation for forming the collective decision matrix. The author applied the presented method to a worked out supplier selection problem. In another paper, Chen ${ }^{40}$ again used the Interval Type-2 fuzzy set technique, which is less precise and more ambiguous version, compared to ordinary fuzzy sets. In that article, the objective importance criteria weights and fuzzy group MCDM problems are determined with a signeddistance-based method in a successful and resilient way. 
These studies are summarized in Table 1. Consequently, the use of Interval Type- 2 trapezoidal fuzzy numbers shows the benefits to represent alternative scores and the significance of miscellaneous criteria in MCDM.

\subsection{Method}

This paper will use an Interval Type-2 TOPSIS technique, which is a modified version of the method proposed by Chen and Lee ${ }^{24}$. The steps of the applied approach are as follows: Step 1: Form a group of experts with $k$ members and set the alternatives and evaluation criteria. Step 2: Establish the evaluation matrix by determining the linguistic variables for weighting criteria and the linguistic ratings for the alternatives as given in Table 2 .

Step 3: Build the decision matrix $Y_{p}$ of the $p$ th decision-maker produced from Table 2 and constitute the average decision matrix $\overline{\boldsymbol{Y}}$, respectively, shown as follows:

$$
\begin{aligned}
& Y_{p}=\left(\tilde{f}_{i j}^{p}\right)_{m \times n}=f_{1}\left[\begin{array}{cccc}
x_{1} & x_{2} & \cdots & x_{n} \\
f_{2} & \vdots \\
f_{m} & \tilde{\tilde{f}}^{p} & \cdots & \tilde{\tilde{f}}_{1 n}^{p} \\
\tilde{\tilde{f}}_{21}^{p} & \tilde{\tilde{f}}^{p} & \cdots & \tilde{\tilde{f}}_{2 n}^{p} \\
\vdots & \vdots & \ddots & \vdots \\
\tilde{\tilde{f}}_{m 1}^{p} & \tilde{\tilde{f}}_{m 2}^{p} & \cdots & \tilde{f}_{m n}^{p}
\end{array}\right] \\
& \overline{\boldsymbol{Y}}=\left(\tilde{\tilde{f}}_{i j}\right)_{m \times n}
\end{aligned}
$$

where $\tilde{\tilde{f}}_{i j}=\left(\frac{\tilde{\tilde{f}}_{i j}^{1} \oplus \tilde{\tilde{f}}_{i j}^{2} \oplus \ldots \oplus \tilde{\tilde{f}}_{i j}^{k}}{k}\right), \tilde{\tilde{f}}_{i j}$ is an Interval Type-2 fuzzy set, $1 \leqslant i \leqslant m, 1 \leqslant j \leqslant n, 1 \leqslant p \leqslant k$ and $k$ represents the number of decision-makers. Step 4 : Constitute the weighting matrix $W_{p}$ of the attributes of the $p$ th decision-maker and constitute the average weighting matrix $\overline{\boldsymbol{W}}$, respectively, shown as follows:

$$
\begin{aligned}
& W_{p}=\left(\tilde{\tilde{w}}_{i}^{p}\right)_{1 \times m}=\left[\begin{array}{cccc}
f_{1} & f_{2} & \cdots & f_{m} \\
{\left[\tilde{\tilde{w}}_{1}^{p}\right.} & \tilde{\tilde{w}}_{2}^{p} & \cdots & \tilde{\tilde{w}}_{n}^{p}
\end{array}\right] \\
& \bar{W}=\left(\tilde{\tilde{w}}_{i}\right)_{1 \times m}
\end{aligned}
$$

where $\tilde{\tilde{w}}_{i}=\left(\frac{\tilde{\tilde{w}}_{i}^{1} \oplus \tilde{\tilde{w}}_{i}^{2} \oplus \ldots \oplus \tilde{\tilde{w}}_{i}^{k}}{k}\right), \tilde{\tilde{w}}_{i}$ is an Interval Type2 fuzzy set, $1 \leqslant i \leqslant m, 1 \leqslant j \leqslant n, 1 \leqslant p \leqslant k$ and $k$ denotes the number of decision-makers. Step 5 : Constitute the weighted decision matrix $\overline{\boldsymbol{Y}}_{w}$,

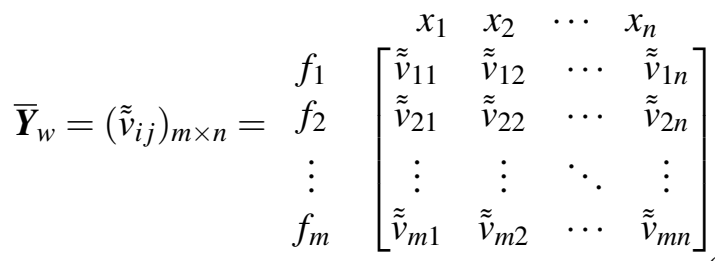

where $\tilde{\tilde{v}}_{i j}=\tilde{\tilde{w}}_{i j} \otimes \tilde{\tilde{f}}_{i j}, 1 \leqslant i \leqslant m, 1 \leqslant j \leqslant n$. Step 6 : Based on Eq. 17 obtained from $\mathrm{Wu}$ and Mendel ${ }^{36}$, calculate the ranking value $\operatorname{Rank}\left(\tilde{\tilde{v}}_{i j}\right)$ of the Interval Type-2 fuzzy set $\tilde{\tilde{v}}_{i j}$, where $1 \leqslant j \leqslant n$.

Then construct the ranking weighted decision matrix $\bar{Y}_{* w}$ :

$$
\bar{Y}_{* w}=\left(\operatorname{Rank}\left(\tilde{\tilde{v}}_{i j}\right)\right)_{m \times n}
$$

where $1 \leqslant i \leqslant m, 1 \leqslant j \leqslant n$. Step 7 : Determine the positive ideal solution $x^{+}=\left(v_{1}^{+}, v_{2}^{+}, \ldots, v_{m}^{+}\right)$and the negative-ideal solution $x^{-}=\left(v_{1}^{-}, v_{2}^{-}, \ldots, v_{m}^{-}\right)$, where:

$$
v_{i}^{+}= \begin{cases}\max _{1 \leqslant j \leqslant n}\left\{\operatorname{Rank}\left(\tilde{\tilde{v}}_{i j}\right)\right\}, & \text { if } f_{i} \in F_{1} \\ \min _{1 \leqslant j \leqslant n}\left\{\operatorname{Rank}\left(\tilde{\tilde{v}}_{i j}\right)\right\}, & \text { if } n \in F_{2}\end{cases}
$$

and

$$
v_{i}^{-}= \begin{cases}\min _{1 \leqslant j \leqslant n}\left\{\operatorname{Rank}\left(\tilde{\tilde{v}}_{i j}\right)\right\}, & \text { if } f_{i} \in F_{1} \\ \max _{1 \leqslant j \leqslant n}\left\{\operatorname{Rank}\left(\tilde{\tilde{v}}_{i j}\right)\right\}, & \text { if } n \in F_{2}\end{cases}
$$

where $F_{1}$ denotes the set of benefit attributes, $F_{2}$ denotes the set of cost attributes, and $1 \leqslant i \leqslant m$. Step 8 : Compute the distance $d^{+}\left(x_{j}\right)$ between each alternative $x_{j}$ and the positive ideal solution $x^{+}$, shown as follows:

$$
d^{+}\left(x_{j}\right)=\sqrt{\sum_{i=1}^{m}\left(\operatorname{Rank}\left(\tilde{\tilde{v}}_{i j}\right)-v_{i}^{+}\right)^{2}}
$$

where $1 \leqslant j \leqslant n$. Compute the distance $d^{-}\left(x_{j}\right)$ between each alternative $x_{j}$ and the negative ideal solution $x^{-}$, shown as follows:

$$
d^{-}\left(x_{j}\right)=\sqrt{\sum_{i=1}^{m}\left(\operatorname{Rank}\left(\tilde{\tilde{v}}_{i j}\right)-v_{i}^{-}\right)^{2}}
$$


Table 1: Summary of recent researches on MCDM studies using Interval Type-2 fuzzy sets.

\begin{tabular}{|c|c|c|}
\hline Researchers & Used methods & Focus area \\
\hline (Baležentis \& Zeng, 2013) $^{46}$ & $\begin{array}{l}\text { Fuzzy MULTIMOORA using } \\
\text { Interval Type-2 fuzzy sets }\end{array}$ & $\begin{array}{l}\text { Personnel selection; an extension } \\
\text { to a crisp MULTIMOORE method. }\end{array}$ \\
\hline$(\text { Cebi 2015) })^{39}$ & $\begin{array}{l}\text { Fuzzy TOPSIS using } \\
\text { Interval Type-2 fuzzy sets }\end{array}$ & Facility location selection problem \\
\hline $\begin{array}{l}\text { (Celik, Bilisik, Erdogan, } \\
\text { Gumus \& Baracli, 2013) }\end{array}$ & $\begin{array}{l}\text { Fuzzy TOPSIS and GRA using } \\
\text { Interval Type- } 2 \text { fuzzy sets }\end{array}$ & $\begin{array}{l}\text { Evaluation of public transportation } \\
\text { and customers satisfaction }\end{array}$ \\
\hline (Celik, Aydin \& Gumus, 2014) $^{42}$ & $\begin{array}{l}\text { Fuzzy VIKOR using Interval } \\
\text { Type-2 fuzzy sets }\end{array}$ & $\begin{array}{l}\text { Evaluate customer satisfaction level for } \\
\text { the rail transit network }\end{array}$ \\
\hline$\left(\right.$ Chen, Chang \& Lu, 2013) ${ }^{41}$ & $\begin{array}{l}\text { Fuzzy QUALIFLEX using Interval } \\
\text { Type-2 fuzzy sets }\end{array}$ & $\begin{array}{l}\text { Medical decision-making problem; } \\
\text { an extension to a traditional } \\
\text { QUALIFLEX method }\end{array}$ \\
\hline$(\text { Chen, 2014) })^{47}$ & $\begin{array}{l}\text { Fuzzy ELECTRE using Interval } \\
\text { Type-2 fuzzy sets }\end{array}$ & Supplier selection problem \\
\hline$\left(\right.$ Chen \& Lee, 2010) ${ }^{24}$ & $\begin{array}{l}\text { Fuzzy TOPSIS using Interval } \\
\text { Type-2 fuzzy sets }\end{array}$ & Evaluation of the cars \\
\hline $\begin{array}{l}\text { (Ghorabaee, Amiri, } \\
\text { Sadaghiani \& Goodarzi, 2014) }\end{array}$ & $\begin{array}{l}\text { Fuzzy COPRAS using Interval } \\
\text { Type-2 fuzzy sets }\end{array}$ & Supplier selection problem \\
\hline $\begin{array}{l}\text { (Kahraman, Öztayşi, Sarı } \\
\text { \& E. Turanoğlu, 2014) }\end{array}$ & $\begin{array}{l}\text { Fuzzy AHP using Interval } \\
\text { Type-2 fuzzy sets }\end{array}$ & Supplier selection problem \\
\hline$(\text { Kuo, } 2011)^{43}$ & $\begin{array}{l}\text { Fuzzy VIKOR and GRA } \\
\text { using Interval Type-2 fuzzy sets }\end{array}$ & $\begin{array}{l}\text { Evaluation of service quality of Chinese } \\
\text { cross-strait passenger airlines }\end{array}$ \\
\hline$(\text { Naim \& Hagras, 2014) })^{21}$. & $\begin{array}{l}\text { Fuzzy TOPSIS using } \\
\text { Interval Type- } 2 \text { fuzzy sets }\end{array}$ & $\begin{array}{l}\text { Illumination selection in an intelligent } \\
\text { shared environment }\end{array}$ \\
\hline
\end{tabular}

where $1 \leqslant j \leqslant n$. Step 9 : Compute the relative degree of closeness $C\left(x_{j}\right)$ of $x_{j}$ with respect to the positive ideal solution $x^{+}$, shown as follows:

$$
C\left(x_{j}\right)=\frac{d^{-}\left(x_{j}\right)}{d^{+}\left(x_{j}\right)+d^{-}\left(x_{j}\right)}
$$

where $1 \leqslant j \leqslant n$. Step 10 : Rank the values of $C\left(x_{j}\right)$ in a descending sequence, where $1 \leqslant j \leqslant n$. The larger the value of $C\left(x_{j}\right)$, the higher the preference of alternative $x_{j}$, where $1 \leqslant j \leqslant n$. Our approach is depicted in Figure 1.

Figure 2 represents the Interval Type-2 linguistic variables of our case study.

\section{A case study: Evaluation of KM tools alternatives}

In this real case, the DMs of ABC Company ${ }^{\dagger}$ an international firm's Turkish branch, are assisted by the proposed evaluation framework in deciding which
$\mathrm{KM}$ product to purchase. ABC Company offers knowledge-based products, systems and solutions, giving internal $\mathrm{KM}$ extraordinary importance. $\mathrm{ABC}$ Company's business model is IT-driven. Therefore, knowledge and its effective management is of utmost importance. There are also other good reasons why $\mathrm{ABC}$ Company is looking for a suitable $\mathrm{KM}$ product. $\mathrm{ABC}$ Company is a global firm and its employees share information by means of various methods besides face to face communication. KM tools involve technology enabled repositories and sharing networks which can help ABC Company to overcome geographical barriers. Changing customer expectations and new market offerings present another motivation for the lookout for a KM solution. Based on these reasonings, ABC Company decided to implement a KM system internally so that its staff can easily access and manage its corporate knowledge and gain experience.

Step 1: The selection of the most suitable KM tool is done by five professionals (DMs) within ABC

\footnotetext{
$\uparrow *$ To provide anonymity, we name this company as Company ABC.
} 


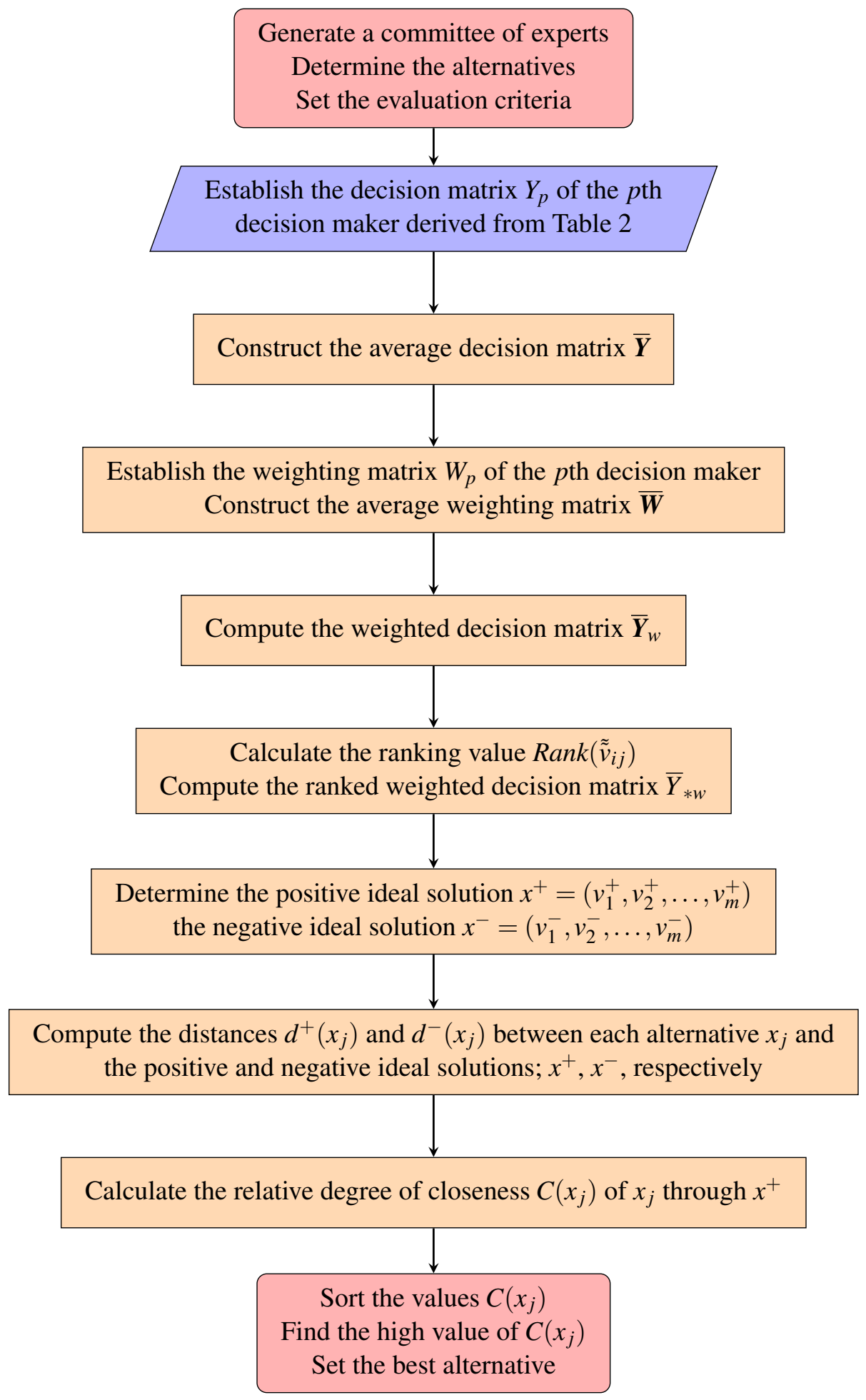

Figure 1: Flowchart of the proposed method. 
Table 2: Linguistic terms and their corresponding Interval Type-2 fuzzy sets.

\begin{tabular}{ccc}
\hline $\begin{array}{c}\text { Linguistic terms for } \\
\text { the weights of the attributes }\end{array}$ & $\begin{array}{c}\text { Linguistic terms } \\
\text { for the ratings }\end{array}$ & Interval Type-2 fuzzy sets \\
\hline Very Low (VL) & Very Poor (VP) & $((0,0,0,0.1 ; 1,1),(0,0,0,0.05 ; 0.9,0.9))$ \\
Low (L) & Fairly Poor (FP) & $((0,0.1,0.1,0.3 ; 1,1),(0.05,0.1,0.1,0.2 ; 0.9,0.9))$ \\
Medium Low (ML) & Poor (P) & $((0.1,0.3,0.3,0.5 ; 1,1),(0.2,0.3,0.3,0.4 ; 0.9,0.9))$ \\
Medium (M) & Moderate (M) & $((0.3,0.5,0.5,0.7 ; 1,1),(0.4,0.5,0.5,0.6 ; 0.9,0.9))$ \\
Medium High (MH) & Good (G) & $((0.5,0.7,0.7,0.9 ; 1,1),(0.6,0.7,0.7,0.8 ; 0.9,0.9))$ \\
High (H) & Fairly Good (FG) & $((0.7,0.9,0.9,1 ; 1,1),(0.8,0.9,0.9,0.95 ; 0.9,0.9))$ \\
Very High (VH) & Very Good (VG) & $((0.9,1,1,1 ; 1,1),(0.95,1,1,1 ; 0.9,0.9))$ \\
\hline
\end{tabular}

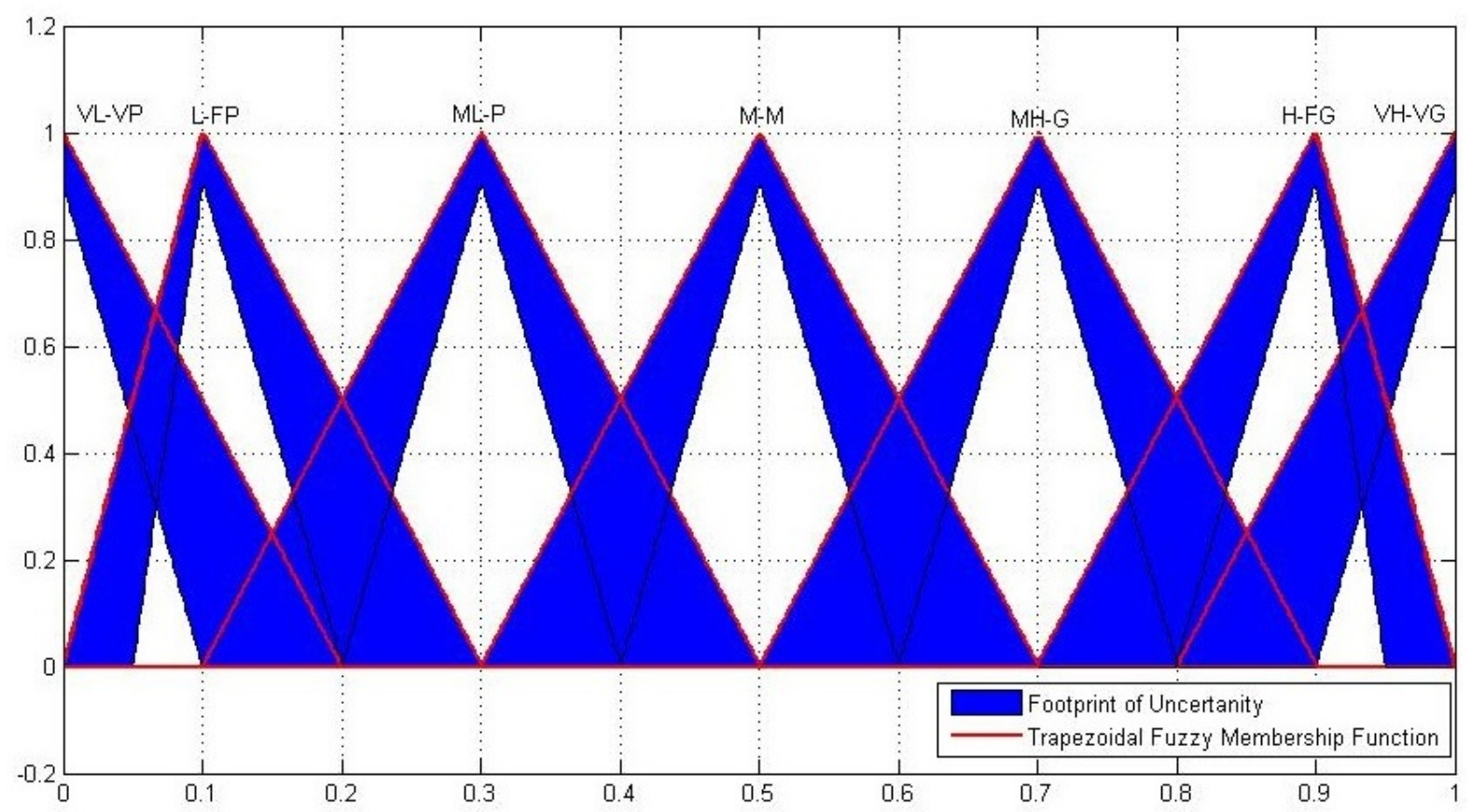

Figure 2: Representation of Interval Type-2 linguistic variables.

Company. The composition of the decision committee is as the following. One member is a top manager because the top managers' active involvement in the KM system adoption process greatly increases its success. Two members are chosen from the IT department based on their experience in corporate change management projects. The other two decision makers are senior managers of the company, who are potential users of the KM tools in future.

Step 2: The KM system selection requires the committee to select a product among others that matches well with the internal needs and requirements. The selected KM system shall also be in line with corporate guidelines and IT architecture, leaving the committee with the following alternatives: IntelliEnterprise by Adenin Technologies (alternative $a_{1}$ ), SharePoint by Microsoft (alternative $a_{2}$ ) and Oracle Beehive by Oracle (alternative $a_{3}$ ). The evaluation criteria are determined as it is summarized in Table 2.

Step 3: Firstly, we start to build up three decision matrices $Y_{1}, Y_{2}$ and $Y_{3}$ for three alternatives $a_{1}$, $a_{2}$ and $a_{3}$, respectively. Afterwards, we compute the average decision matrix $\tilde{Y}$ in order to have the cor- 
responding Type- 2 representations as follows;

$\tilde{\tilde{f}}_{11}=((0.38,0.58,0.7,0.78,1,1),(0.48,0.58,0.68,0.68,0.9,0.9))$, $\tilde{\tilde{f}}_{12}=((0.04,0.16,0.16,0.34,1,1),(0.1,0.16,0.16,0.34,0.9,0.9))$, $\tilde{\tilde{f}}_{13}=((0.46,0.66,0.74,0.84,1,1),(0.56,0.66,0.74,0.75,0.9,0.9))$, $\tilde{\tilde{f}}_{21}=((0.82,0.94,0.94,0.98,1,1),(0.88,0.94,0.96,0.96,0.9,0.9))$, $\tilde{\tilde{f}}_{22}=((0.02,0.08,0.08,0.22,1,1),(0.05,0.08,0.08,0.42,0.9,0.9))$, $\tilde{\tilde{f}}_{23}=((0.02,0.08,0.08,0.22,1,1),(0.05,0.08,0.08,0.42,0.9,0.9))$, $\tilde{\tilde{f}}_{31}=((0.46,0.66,0.74,0.84,1,1),(0.56,0.66,0.74,0.75,0.9,0.9))$, $\tilde{\tilde{f}}_{32}=((0,0.04,0.04,0.18,1,1),(0.02,0.04,0.04,0.38,0.9,0.9))$, $\tilde{\tilde{f}}_{33}=((0.46,0.66,0.74,0.84,1,1),(0.56,0.66,0.74,0.75,0.9,0.9))$, $\tilde{\tilde{f}}_{41}=((0.58,0.76,0.8,0.9,1,1),(0.67,0.76,0.82,0.83,0.9,0.9))$, $\tilde{\tilde{f}}_{42}=((0,0.06,0.06,0.22,1,1),(0.03,0.06,0.06,0.32,0.9,0.9))$, $\tilde{f}_{43}=((0.42,0.62,0.7,0.82,1,1),(0.52,0.62,0.72,0.72,0.9,0.9))$, $\tilde{f}_{51}=((0.04,0.16,0.16,0.34,1,1),(0.1,0.16,0.16,0.34,0.9,0.9))$, $\tilde{\tilde{f}}_{52}=((0.46,0.66,0.74,0.84,1,1),(0.56,0.66,0.74,0.75,0.9,0.9))$, $\tilde{\tilde{f}}_{53}=((0.38,0.58,0.62,0.78,1,1),(0.48,0.58,0.66,0.68,0.9,0.9))$, $\tilde{\tilde{f}}_{61}=((0.24,0.42,0.5,0.62,1,1),(0.33,0.42,0.48,0.52,0.9,0.9))$, $\tilde{\tilde{f}}_{62}=((0.26,0.46,0.54,0.66,1,1),(0.36,0.46,0.52,0.56,0.9,0.9))$, $\tilde{\tilde{f}}_{63}=((0.46,0.66,0.74,0.84,1,1),(0.56,0.66,0.74,0.75,0.9,0.9))$, $\tilde{\tilde{f}}_{71}=((0.06,0.22,0.22,0.42,1,1),(0.14,0.22,0.22,0.32,0.9,0.9))$, $\tilde{\tilde{f}}_{72}=((0.58,0.76,0.8,0.9,1,1),(0.67,0.76,0.82,0.83,0.9,0.9))$, $\tilde{\tilde{f}}_{73}=((0.2,0.38,0.42,0.58,1,1),(0.29,0.38,0.42,0.48,0.9,0.9))$, $\tilde{\tilde{f}}_{\tilde{~}}=((0.74,0.88,0.88,0.96,1,1),(0.81,0.88,0.92,0.92,0.9,0.9))$, $\tilde{f}_{82}=((0.04,0.14,0.14,0.3,1,1),(0.09,0.14,0.14,0.4,0.9,0.9))$, $\tilde{\tilde{f}}_{83}=((0.06,0.2,0.2,0.38,1,1),(0.13,0.2,0.2,0.38,0.9,0.9))$, $\tilde{\tilde{f}}_{91}=((0.46,0.66,0.74,0.84,1,1),(0.56,0.66,0.74,0.75,0.9,0.9))$, $\tilde{\tilde{f}}_{92}=((0.18,0.32,0.32,0.48,1,1),(0.25,0.32,0.32,0.49,0.9,0.9))$, $\tilde{\tilde{f}}_{93}=((0.38,0.58,0.7,0.78,1,1),(0.48,0.58,0.68,0.68,0.9,0.9))$, $\tilde{\tilde{f}}_{101}=((0.42,0.62,0.7,0.82,1,1),(0.52,0.62,0.72,0.72,0.9,0.9))$, $\tilde{\tilde{f}}_{102}=((0.58,0.76,0.8,0.9,1,1),(0.67,0.76,0.82,0.83,0.9,0.9))$ $\tilde{\tilde{f}}_{103}=((0.04,0.14,0.14,0.3,1,1),(0.09,0.14,0.14,0.4,0.9,0.9))$

Step 4: We calculate the average weighting ma$\operatorname{trix} \tilde{W}=\left[\tilde{\tilde{w}}_{1} \tilde{\tilde{w}}_{2} \tilde{\tilde{w}}_{3} \tilde{\tilde{w}}_{4} \tilde{\tilde{w}}_{5} \tilde{\tilde{w}}_{6} \tilde{\tilde{w}}_{7} \tilde{\tilde{w}}_{8} \tilde{\tilde{w}}_{9} \tilde{\tilde{w}}_{10}\right]$ where

$\tilde{w}_{1}=((00.060 .060 .2211),(0.030 .060 .060 .320 .90 .9))$,

$\tilde{\tilde{w}}_{2}=((0.82,0.96,0.96,1,1,1),(0.89,0.96,0.96,0.98,0.9,0.9))$, $\tilde{\tilde{w}}_{3}=((0.62,0.82,0.86,0.94,1,1),(0.72,0.82,0.84,0.88,0.9,0.9))$, $\tilde{w}_{4}=((0.32,0.5,0.62,0.68,1,1),(0.41,0.5,0.56,0.59,0.9,0.9))$, $\tilde{\tilde{w}}_{5}=((0.38,0.58,0.74,0.76,1,1),(0.48,0.58,0.66,0.67,0.9,0.9))$, $\tilde{\tilde{w}}_{6}=((0,0.02,0.02,0.14,1,1),(0.01,0.02,0.02,0.44,0.9,0.9))$, $\tilde{\tilde{w}}_{7}=((0.46,0.66,0.78,0.82,1,1),(0.56,0.66,0.72,0.74,0.9,0.9))$, $\tilde{\tilde{w}}_{8}=((0.2,0.34,0.38,0.52,1,1),(0.27,0.34,0.36,0.43,0.9,0.9))$, $\tilde{\tilde{w}}_{9}=((0.46,0.66,0.78,0.82,1,1),(0.56,0.66,0.72,0.74,0.9,0.9))$, $\tilde{\tilde{w}}_{10}=((0.82,0.96,0.96,1,1,1),(0.89,0.96,0.96,0.98,0.9,0.9))$

Step 5: We compute the weighted decision ma- $\operatorname{trix} \tilde{Y}_{W}$

$\tilde{y}_{11}=((0,0.03,0.04,0.17,1,1),(0.010 .030 .040 .220 .90 .9))$,

$\tilde{\tilde{y}}_{12}=((0,0.01,0.01,0.07,1,1),(0.01,0.01,0.01,0.10,0.9,0.9))$,

$\tilde{\tilde{y}}_{13}=((0,0.04,0.04,0.18,1,1),(0.02,0.04,0.04,0.24,0.9,0.9))$,

$\tilde{\tilde{y}}_{21}=((0.67,0.90,0.90,0.98,1,1),(0.78,0.90,0.92,0.94,0.9,0.9))$,

$\tilde{y}_{22}=((0.02,0.08,0.08,0.22,1,1),(0.04,0.08,0.08,0.42,0.9,0.9))$,

$\tilde{\tilde{y}}_{23}=((0.02,0.08,0.08,0.22,1,1),(0.04,0.08,0.08,0.41,0.9,0.9))$,

$\tilde{\tilde{y}}_{31}=((0.28,0.54,0.64,0.79,1,1),(0.40,0.54,0.62,0.66,0.9,0.9))$,

$\tilde{y}_{32}=((0,0.03,0.03,0.17,1,1),(0.01,0.03,0.03,0.34,0.9,0.9))$,

$\tilde{y}_{33}=((0.28,0.54,0.64,0.79,1,1),(0.40,0.54,0.62,0.66,0.9,0.9))$,

$\tilde{\tilde{y}}_{41}=((0.18,0.38,0.50,0.61,1,1),(0.27,0.38,0.46,0.49,0.9,0.9))$,

$\tilde{\tilde{y}}_{42}=((0,0.03,0.04,0.15,1,1),(0.01,0.03,0.03,0.19,0.9,0.9))$,

$\tilde{y}_{43}=((0.13,0.31,0.43,0.55,1,1),(0.21,0.31,0.40,0.42,0.9,0.9))$,

$\tilde{\tilde{y}}_{51}=((0.01,0.09,0.12,0.25,1,1),(0.05,0.09,0.10,0.22,0.9,0.9))$,

$\tilde{y}_{52}=((0.17,0.38,0.55,0.64,1,1),(0.27,0.38,0.49,0.50,0.9,0.9))$,

$\tilde{\tilde{y}}_{53}=((0.14,0.34,0.46,0.59,1,1),(0.23,0.34,0.44,0.4,0.9,0.9))$,

$\tilde{\tilde{y}}_{61}=((0,0.01,0.01,0.09,1,1),(0,0.01,0.01,0.22,0.9,0.9))$,

$\tilde{\tilde{y}}_{62}=((0,0.01,0.01,0.09,1,1),(0,0.01,0.01,0.24,0.9,0.9))$,

$\tilde{\tilde{y}}_{63}=((0,0.01,0.01,0.12,1,1),(0,0.01,0.01,0.33,0.9,0.9))$,

$\tilde{\tilde{y}}_{71}=((0.03,0.14,0.17,0.34,1,1),(0.08,0.14,0.16,0.24,0.9,0.9))$,

$\tilde{y}_{72}=((0.27,0.50,0.62,0.74,1,1),(0.37,0.50,0.59,0.61,0.9,0.9))$,

$\tilde{\tilde{y}}_{73}=((0.09,0.25,0.32,0.47,1,1),(0.16,0.25,0.30,0.35,0.9,0.9))$,

$\tilde{\tilde{y}}_{81}=((0.15,0.3,0.33,0.5,1,1),(0.22,0.3,0.33,0.4,0.9,0.9))$,

$\tilde{y}_{82}=((0.01,0.04,0.05,0.15,1,1),(0.02,0.04,0.05,0.17,0.9,0.9))$,

$\tilde{\tilde{y}}_{83}=((0.01,0.06,0.07,0.19,1,1),(0.03,0.06,0.07,0.16,0.9,0.9))$,

$\tilde{\tilde{y}}_{91}=((0.21,0.43,0.58,0.68,1,1),(0.31,0.43,0.53,0.55,0.9,0.9))$,

$\tilde{\tilde{y}}_{92}=((0.08,0.21,0.24,0.39,1,1),(0.14,0.21,0.23,0.36,0.9,0.9)$,

$\tilde{\tilde{y}}_{93}=((0.17,0.38,0.54,0.64,1,1),(0.27,0.38,0.49,0.50,0.9,0.9))$,

$\tilde{\tilde{y}}_{101}=((0.34,0.6,0.67,0.82,1,1),(0.46,0.6,0.69,0.7,0.9,0.9))$,

$\tilde{y}_{102}=((0.47,0.73,0.76,0.9,1,1),(0.6,0.73,0.78,0.81,0.9,0.9))$,

$\tilde{y}_{103}=((0.03,0.13,0.13,0.3,1,1),(0.08,0.13,0.13,0.39,0.9,0.9))$,

Step 6: Firstly, we construct the ranking weighted decision matrix $\tilde{Y}_{w}^{*}$ based on the centroid method;

\begin{tabular}{|c|c|c|c|c|}
\hline \multirow{10}{*}{$\tilde{Y}_{w}^{*}=$} & Software enhancement & \multicolumn{2}{|r|}{$\begin{array}{l}a_{1} \quad a_{2} \\
\quad \tilde{R}_{3}\end{array}$} & $\operatorname{Rank}\left(\tilde{\tilde{v}}_{13}\right)$ \\
\hline & Compliance & $\operatorname{Rank}\left(\tilde{\tilde{v}}_{21}\right)$ & $\operatorname{Rank}\left(\tilde{\tilde{v}}_{22}\right)$ & $\operatorname{Rank}\left(\tilde{\tilde{v}}_{23}\right)$ \\
\hline & Document management & $\operatorname{Rank}\left(\tilde{\tilde{v}}_{11}\right)$ & $\operatorname{Rank}\left(\tilde{v}_{32}\right)$ & $\operatorname{Rank}\left(\tilde{\tilde{v}}_{33}\right)$ \\
\hline & Collaboration facilities & $\operatorname{Rank}\left(\tilde{\tilde{v}}_{41}\right)$ & $\operatorname{Rank}\left(\tilde{\tilde{v}}_{42}\right)$ & $\operatorname{Rank}\left(\tilde{\tilde{v}}_{43}\right)$ \\
\hline & Portal functions & $\operatorname{Rank}\left(\tilde{\tilde{v}}_{51}\right)$ & $\operatorname{Rank}\left(\tilde{v}_{52}\right)$ & $\operatorname{Rank}\left(\tilde{\tilde{v}}_{53}\right)$ \\
\hline & Workflow facilities & $\operatorname{Rank}\left(\tilde{\tilde{v}}_{61}\right)$ & $\operatorname{Rank}\left(\tilde{\tilde{v}}_{62}\right)$ & $\operatorname{Rank}\left(\tilde{\tilde{V}}_{63}\right)$ \\
\hline & Ease of use & $\operatorname{Rank}\left(\tilde{\tilde{v}}_{71}\right)$ & $\operatorname{Rank}\left(\tilde{\tilde{v}}_{72}\right)$ & $\operatorname{Rank}\left(\tilde{\tilde{v}}_{73}\right.$ \\
\hline & Capital expenditure & $\operatorname{Rank}\left(\tilde{\tilde{v}}_{81}\right)$ & $\operatorname{Rank}\left(\tilde{\tilde{v}}_{82}\right)$ & $\operatorname{Rank}\left(\tilde{\tilde{v}}_{83}\right.$ \\
\hline & Operating expenditure & $\operatorname{Rank}\left(\tilde{v}_{91}\right)$ & $\operatorname{Rank}\left(\tilde{\tilde{v}}_{92}\right)$ & $\operatorname{Rank}\left(\tilde{\nu}_{93}\right.$ \\
\hline & Vendor reputation & & Rank & Rank \\
\hline
\end{tabular}

We obtain the following matrix;

\begin{tabular}{|c|c|c|c|c|}
\hline & & $a_{1}$ & $a_{2}$ & $a_{3}$ \\
\hline & Software enhancement & $\lceil 0.07$ & 0.03 & 0.087 \\
\hline & Compliance & 0.86 & 0.12 & 0.12 \\
\hline & Document management & 0.55 & 0.08 & 0.55 \\
\hline & Collaboration facilities & 0.41 & 0.06 & 0.34 \\
\hline \multirow{6}{*}{$\tilde{Y}_{w}^{*}=$} & Portal functions & 0.12 & 0.42 & 0.37 \\
\hline & Workflow facilities & 0.03 & 0.04 & 0.05 \\
\hline & Ease of use & 0.16 & 0.52 & 0.27 \\
\hline & Capital expenditure & 0.31 & 0.07 & 0.09 \\
\hline & Operating expenditure & 0.46 & 0.23 & 0.42 \\
\hline & Vendor reputation & L 0.6 & 0.71 & 0.17 \\
\hline
\end{tabular}


Table 3: Representation of the alternatives by the evaluation of 5 different experts $x_{1}, x_{2}, x_{3}, x_{4}$ and $x_{5}$.

$\left.\mathrm{Y}_{1}=\begin{array}{ccccccc}x_{1} & x_{2} & x_{3} & x_{4} & x_{5} \\ \text { Software enhancement } & \text { Compliance } & \mathrm{G} & \mathrm{M} & \mathrm{M} & \mathrm{M} & \mathrm{G} \\ \text { Document management } & \mathrm{VG} & \mathrm{VG} & \mathrm{VG} & \mathrm{G} & \mathrm{VG} \\ \text { Pollaboration facilities } & \mathrm{FG} & \mathrm{G} & \mathrm{M} & \mathrm{M} & \mathrm{VG} \\ \text { Portal functions } & \mathrm{FG} & \mathrm{VG} & \mathrm{G} & \mathrm{G} & \mathrm{M} \\ \text { Workflow facilities } & \mathrm{FP} & \mathrm{P} & \mathrm{P} & \mathrm{VP} & \mathrm{FP} \\ \text { Ease of use } & \mathrm{M} & \mathrm{G} & \mathrm{M} & \mathrm{FP} & \mathrm{P} \\ \text { Capital expenditure } & \mathrm{P} & \mathrm{FP} & \mathrm{P} & \mathrm{P} & \mathrm{FP} \\ \text { Operating expenditure } & \mathrm{VG} & \mathrm{VG} & \mathrm{G} & \mathrm{VG} & \mathrm{G} \\ \text { Vendor reputation } & \mathrm{G} & \mathrm{G} & \mathrm{FG} & \mathrm{M} & \mathrm{M} \\ \mathrm{M} & \mathrm{G} & \mathrm{M} & \mathrm{G} & \mathrm{G}\end{array}\right]$

$$
\mathrm{Y}_{3}=\begin{aligned}
& \text { Software enhancement } \\
& \text { Compliance } \\
& \text { Document management } \\
& \text { Collaboration facilities } \\
& \text { Portal functions } \\
& \text { Workflow facilities } \\
& \text { Ease of use } \\
& \text { Capital expenditure } \\
& \text { Operating expenditure } \\
& \text { Vendor reputation }
\end{aligned}
$$

Secondly, we apply the ranking method proposed by Chen and $\mathrm{Lee}^{24}$ and obtain the following matrix;

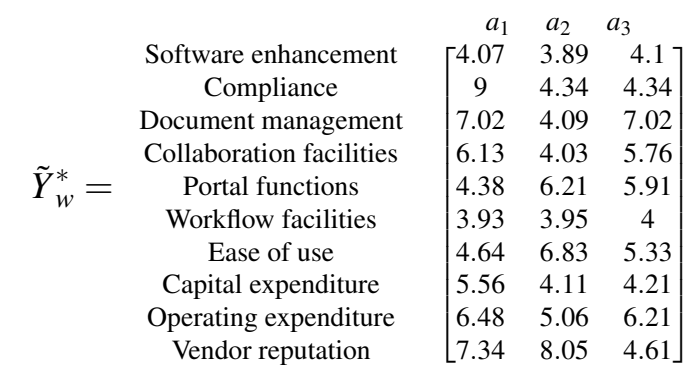

Step 7: We start to calculate the positive $x^{+}$and the negative $x^{-}$ideal solutions for both methods.

The ideal solutions with the centroid approach are;

$$
\begin{aligned}
& x^{+}=0.08,0.86,0.55,0.4,0.42,0.05,0.52,0.31,0.46,0.71 \\
& x^{+}=0.03,0.12,0.08,0.06,0.12,0.03,0.16,0.07,0.23,0.17
\end{aligned}
$$

Furthermore, we find the ideal solutions based on the method Chen and Lee ${ }^{24}$;

$$
\begin{aligned}
& x^{+}=4.1,9,7.02,6.13,6.21,4,6.83,5.56,6.48,8.05 \\
& x^{-}=3.89,4.34,4.09,4.03,4.38,3.93,4.64,4.11,5.06,4.61
\end{aligned}
$$

Step 8: In order to sort the results we start to calculate the distances between each alternative and both ideal solutions. $d_{a_{1}}^{+}=0.88 d_{a_{2}}^{+}=1.44 d_{a_{3}}^{+}=$ $1.38 d_{a_{1}}^{-}=1.58 d_{a_{2}}^{-}=1.09 d_{a_{3}}^{-}=1.17$

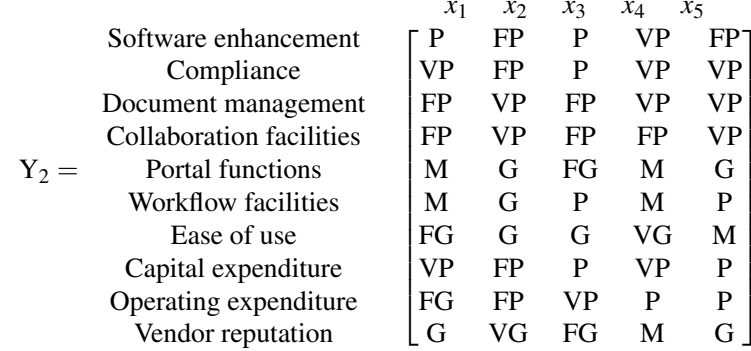

$$
\begin{aligned}
& \begin{array}{lllll}
x_{1} & x_{2} & x_{3} & x_{4} & x_{5}
\end{array} \\
& {\left[\begin{array}{ccccc}
M & M & F G & G & G \\
\text { FP } & \text { VP } & \text { VP } & \text { P } & \text { VP } \\
\text { G } & \text { FG } & \text { G } & \text { M } & \text { M } \\
\text { G } & \text { G } & \text { M } & \text { G } & \text { M } \\
\text { G } & \text { G } & \text { P } & \text { M } & \text { G } \\
\text { FG } & \text { G } & \text { M } & \text { M } & \text { G } \\
\text { M } & \text { G } & \text { P } & \text { FP } & \text { P } \\
\text { P } & \text { FP } & \text { P } & \text { P } & \text { VP } \\
\text { G } & \text { M } & \text { G } & \text { M } & \text { M } \\
\text { FP } & \text { P } & P & \text { VP } & \text { VP }
\end{array}\right]}
\end{aligned}
$$

Moreover, we repeat the same procedure for the method of Chen and Lee ${ }^{24}$ and we find the following results; $d_{a_{1}}^{+}=2.19 d_{a_{2}}^{+}=3.57 d_{a_{3}}^{+}=3.44 d_{a_{1}}^{-}=3.93$ $d_{a_{2}}^{-}=2.73 d_{a_{3}}^{-}=2.89$

These values are illustrated in Figure 2. It seems that our method offers small values for distances.

Step 9: We calculate the degree of closeness of each alternative $C\left(a_{1}\right)=0.64 C\left(a_{2}\right)=0.42 C\left(a_{3}\right)=$ 0.46

Afterwards, we find the degrees of closeness by the method of Chen and Lee; $C\left(a_{1}\right)=0.64 C\left(a_{2}\right)=$ $0.43 C\left(a_{3}\right)=0.45$

Step 10: Finally, we sort the degrees of closeness. For both approaches, we find that $C\left(a_{1}\right)>$ $C\left(a_{3}\right)>C\left(a_{2}\right)$. Consequently, we conclude that $a_{1}$ is the best choice.

\subsection{Comparative analysis and discussion}

In this part of our study, the effectiveness of the proposed method is validated with other approaches. Our seven scale linguistic terms are used to measure the variations within the KM framework. In this section, we will compare our proposed method with Type-2 fuzzy TOPSIS method proposed by Chen and $\mathrm{Lee}^{24}$, Type-1 TOPSIS proposed by Chen et al. 48 and classical crisp TOPSIS. 
The first analysis was achieved using the method of Chen and $\mathrm{Lee}^{24}$. We applied their developed Type-2 Fuzzy TOPSIS method to obtain rankings in KM problem. Two methodologies yielded similar ranking results, however the positive and negative distances were different. In our proposed method, the distances were found to be approximately two times smaller than Chen and Lee ${ }^{24}$.

The second comparative analysis was performed with the fuzzy TOPSIS method of Chen et al. 48. This pioneering study highlighted an extended method of classical TOPSIS to study the supplier selection problem. They started with the use of linguistic variable in order to assess the status of each supplier through the corresponding closeness coefficient. Our comparison with this approach concluded the similar rankings. However, the values of Chen et al. ${ }^{48}$ for the closeness were approximately two times smaller than our method.

The last comparative analysis concerns the computation of the classical crisp TOPSIS method. We obtained the similar ranking for the closeness, but our findings were found to be smaller.

Finally, the proposed Type-2 Fuzzy TOPSIS method which is based on the centroid method is found to be consistent in KM framework. All methods give $a_{1}>a_{3}>a_{2}$ for the ranking. As all comparative results indicate the validity of our method, the ranking of the alternatives do not differ, but the scale of optimum distances might vary. Moreover, we note that the proposed method provides stable decisions and does not need additional steps. Therefore, we might conclude that it is distinguishable among the existing MCDA applications.

\section{Conclusion}

The importance of KM tools is increasing within the realms of corporate world, as competitive business environment forces businesses to operate more efficiently and effectively. There exist many solutions for companies seeking KM solutions, however the question remain which of these solutions fits best to the specific needs of the organization.

This study proposed a group decision framework based on the Interval Type-2 fuzzy TOPSIS method for evaluating and selecting a suitable KM tool. In order to check the usability of the proposed framework, it is applied in a real case of company. It should be emphasized that although the proposed framework is developed for this specific KM tool selection problem, it can also be extended to evaluate other kinds of software.

In our study, we integrated the new centroid based ranking method of $\mathrm{Wu}$ and Mendel ${ }^{36}$ as a new approach for Interval Type-2 fuzzy TOPSIS analysis. This method considers the centroids of the Interval Type-2 fuzzy sets. We preferred to use this method as it satisfies all Type- 2 properties and it seems to be more feasible in large scale terms with respect to other methods. It is also notable that this method provides a robust analysis in comparative studies. Furthermore, we compared our study with the method proposed by Chen and $\mathrm{Lee}^{24}$. This step included the substitution of ranking method of $\mathrm{Wu}$ and Mendel ${ }^{36}$. For the following steps, we remarked that our approach provided more normalized values. On the other hand, both methods offered same ranking order. Finally, we conclude the same remark of $\mathrm{Wu}$ and Mendel ${ }^{36}$ by stating that our method could be an alternative choice in Type-2 TOPSIS studies. As future research, the methodology based on Interval Type-2 fuzzy logic can be combined with other MCDM techniques on the problem of KM tool selection, and results can be compared to the findings of this article.

\section{Acknowledgment}

The authors would like to kindly thank for the financial contribution of the Galatasaray University Research Fund (Projects 14.402.004 and 15.402.003), for the support of ABC Company and its KM system selection committee members.

\section{References}

1. I. Nonaka and H. Takeuchi, "The knowledge creating company," Oxford University Press, New York, (1995).

2. P. Drucker, "Management Challenges for the 21st Century," Harper Business, (1999). 
3. L. Edvinsson, "Corporate Longitude," Prentice Hall, London, (2002).

4. T. Chang and T. Wang, "Using the fuzzy multicriteria decision making approach for measuring the possibility of successful knowledge management," Information Sciences, 179, 355-370 (2009).

5. Z. Fan, B. Feng, Y. Sun and W. Ou, "Evaluating knowledge management capability of organizations: a fuzzy linguistic method," Expert Systems with Applications, 36, 3346-3354 (2009).

6. M. Alavi and D. E. Leidner, "Review: Knowledge management and knowledge management systems: Conceptual foundations and research issues," MIS Quarterly, 25, 107 - 136 (2001).

7. L. Rao and K. O. Bryson, "Towards defining dimensions of knowledge systems quality," Expert Systems with Applications, 33, 368-378 (2007).

8. S. Tseng, "The effects of information technology on knowledge management systems," Expert Systems with Applications, 35, 150-160 (2008).

9. P. Tyndale, "A taxonomy of knowledge management software tools: origins and applications," Evaluation and Program Planning, 25, 183-190 (2002).

10. A. Gunasekaran and E. Ngai, "Information systems in supply chain integration and management," European Journal of Operational Research, 159, 269-295 (2004).

11. S. Patil and R. Kant, "A hybrid approach based on fuzzy dematel and fmcdm to predict success of knowledge management adoption in supply chain," Applied Soft Computing, 18, 126-135 (2014).

12. E. Ngai and E. Chan, "Evaluation of knowledge management tools using ahp," Expert Systems with Applications 29, 889-899 (2005).

13. X. Liu and Y. Peng, "Fuzzy ahp method of comprehensive evaluation of knowledge management systems," Journal of Academic Library and Information Science, 23, 5-7 (2005).

14. M. Yu, "Extension evaluation method for knowledge management system of enterprise," Sci-Tech Information Development \& Economy, 20, 99-102 (2010).

15. G. Büyüközkan, O. Feyzioğlu, and G. Çifçi, "Fuzzy multi-criteria evaluation of knowledge management tools," International Journal of Computational Intelligence Systems, 4, 184-195 (2011).

16. M. Li, L. Jin and J. Wang, "A new medm method combining qfd with topsis for knowledge management system selection from the user's perspective in intuitionistic fuzzy environment," Applied Soft Computing, 21, 28-37 (2014).

17. S. Chen and C. Hwang, "Fuzzy Multiple Attribute Decision Making: Methods and Applications," Springer-Verlag, Berlin, (1992).

18. L. A. Zadeh, "Fuzzy sets," Information and Control,
8, 338-353 (1965).

19. L. A. Zadeh, "The concept of a linguistic variable and its application to approximate reasoning-1," Information Sciences, 8, 199-249 (1975).

20. J. M. Mendel, R. I. John and F. L. Liu, "Interval type-2 fuzzy logic systems made simple," IEEE Transactions on Fuzzy Systems, 14, 808-821 (2006).

21. S. Naim and H. Hagras, "A type-2 hesitation fuzzy logic based multi-criteria group decision making system for intelligent shared environments," Soft Computing, 18, 1305-1319 (2014).

22. C. Hwang and K. Yoon, "Multiple attribute decision making methods and applications," Springer-Verlag, Berlin, (1981).

23. P. Sen and J. Yang, "Multiple criteria decision support in engineering design," Springer - Verlag London Limited, London, Great Britain, (1998).

24. S. M. Chen and L. W. Lee, "Fuzzy multiple attributes group decision-making based on the interval type-2 topsis method," Expert Systems with Applications, 37, 2790-2798 (2010).

25. K. Chatterjee and S. Kar, "A hybrid medm approach for selection of financial institution in supply chain risk management," IEEE International Conference on Fuzzy Systems, (2010).

26. E. Celik, O. Bilisik, M. Erdogan, A. Gumus and H. Baracli, "An integrated novel interval type-2 fuzzy mcdm method to improve customer satisfaction in public transportation for Istanbul," Transportation Research Part E: Logistics and Transportation Review, 58, 28-51 (2013).

27. T. Saaty, "The analytic hierarchy process," McGraw-Hill, New York, (1980).

28. G. Büyüközkan and O. Feyzioğlu, "A decision framework for the evaluation of the knowledge management tools," PICMET 2008 Conference Proceedings, 1075-1084 (2008).

29. T. Dereli, A. Baykasoglu, A. Durmusoglu and I. Turksen, "Industrial applications of type-2 fuzzy sets and systems: A concise review," Computers in Industry, 62, 125-137 (2011).

30. R. Ruggles, "Knowledge management tools," Butterworth-Heinemann, Oxford, (1997).

31. J. Sarkis and R. Sundarraj, "Factors for strategic evaluation of enterprise information technologies," International Journal of Physical Distribution and Logistics Management, 30, 196-220 (2000).

32. J. Sarkis and S. Talluri, "Evaluating and selecting ecommerce software and communication systems for a supply chain," European Journal of Operational Research, 159, 318-329 (2004).

33. M. Tam and V. Tummala, "An application of the ahp in vendor selection of a telecommunications system," Omega, 29, 171-182 (2001).

34. H. Lin, P. Y. Hsu and G. J. Sheen, "A fuzzy-based 
decision-making procedure for data warehouse system selection," Expert Systems with Applications, 32, 939-953 (2007).

35. C. G. Sen, H. Baracli, S. Sen and H. Basligil, "An integrated decision support system dealing with qualitative and quantitative objectives for enterprise software selection," Expert Systems with Applications, 36, 5272-5283 (2009).

36. D. Wu and J. M. Mendel, "A comparative study of ranking methods, similarity measures and uncertainty measures for interval type-2 fuzzy sets," Information Sciences, 179, 1169-1192 (2009).

37. L. W. Lee and S. M. Chen, "A new method for fuzzy multiple attribute group decision-making based on the arithmetic operations of interval type-2 fuzzy sets," Proc. Int. Conf. Machine Learning and Cybernetics, 3084-3089 (2008).

38. R. R. Yager, "Ranking fuzzy subsets over the unit interval," Proc. IEEE Conference on Decision and Control, 17, 1435-1437 (1978).

39. F. Cebi and I. Otay, "Multi-Criteria and Multi-Stage Facility Location Selection under Interval Type-2 Fuzzy Environment: A Case Study for a Cement Factory," International Journal of Computational Intelligence Systems, 8, 330-344 (2015).

40. T. Y. Chen, "A signed-distance-based approach to importance assessment and multi-criteria group decision analysis based on interval type-2 fuzzy set," Knowledge and Information Systems, 35, 193-231 (2013).

41. T. Y. Chen, C. H. Chang and J. R. Lu, "The extended $\{$ QUALIFLEX method for multiple criteria decision analysis based on interval type-2 fuzzy sets and applications to medical decision making," Euro- pean Journal of Operational Research, 226, 615-625 (2013).

42. E. Celik, N. Aydin and A. T. Gumus, "A multiattribute customer satisfaction evaluation approach for rail transit network: A real case study for Istanbul, Turkey," Transport Policy, 36, 283-293 (2014).

43. M. S. Kuo, "A novel interval-valued fuzzy mcdm method for improving airlines' service quality in chinese cross-strait airlines," Transportation Research Part E: Logistics and Transportation Review, 47, 1177-1193 (2011)

44. C. Kahraman, B. Öztayşi, İ U Sarı and E. Turanoğlu, "Fuzzy analytic hierarchy process with interval type-2 fuzzy sets," Knowledge-Based Systems, 59, 48-57 (2014).

45. M. Ghorabaee, M. Amiri, J. S. Sadaghiani and G. Goodarzi, "Multiple criteria group decision-making for supplier selection based on copras method with interval type-2 fuzzy sets," The International Journal of Advanced Manufacturing Technology, 75, 11151130 (2014).

46. T. Baležentis and S. Zeng, "Group multi-criteria decision making based upon interval-valued fuzzy numbers: an extension of the multimoora method," Expert Systems with Applications, 40, 543-550 (2013).

47. T. Y. Chen, "An electre-based outranking method for multiple criteria group decision making using interval type-2 fuzzy sets," Information Sciences, 263, 1-21 (2014).

48. C. T. Chen, C. T. Lin and S. Huang, "A fuzzy approach for supplier evaluation and selection in supply chain management," International Journal of Production Economics, 102, 289-301 (2006). 